\title{
Rabab Pasisia sebagai Pertunjukan Seni Tutur di Kabupaten Pesisir Selatan
}

\author{
Hartitom ${ }^{1}$, G.R. Lono L. Simatupang, dan Victor Ganap \\ Program Studi Pengkajian Seni Pertunjukan dan Seni Rupa \\ Sekolah Pascasarjana Universitas Gadjah Mada
}

\begin{abstract}
Rabab Pasisia as a Tutur Art Show in The Pesisir Selatan District. The research has come-up with the conclusion that cotinuity and change in Pesisir Selatan rabab performance, particularly in sub-district of Lengayang has been expanded to a multifunctional arts. Sikambang song has become a means of communal expression in Pesisir Selatan, with its certain local meanings and philosophy of life. Some genre of popular-art has been found-out as integrated in the musical style, in order to maintain attractiveness amongst the West Sumatera community and survival for its musicians and its Pesisir Selatan supporting society.
\end{abstract}

Keywords: rabab; pasisia; sikambang; tutur

\begin{abstract}
ABSTRAK
Tujuan penulisan ini untuk menganalisis keberlangsungan dan perubahan pada pertunjukan Rabab Pasisia di Kabupaten Pesisir Selatan. Rabab Pasisia tetap memiliki daya tarik di tengah masyarakat Sumatera Barat dan merupakan satu cara bertahan hidup bagi para seniman dan masyarakat pendukung kesenian Pesisir Selatan. Nyanyian Sikambang merupakan ungkapan bermakna komunal bagi masyarakat Pesisir Selatan yang memiliki makna filosofi kehidupan dan pengertian lokal tertentu. Beberapa gaya seni populer ditemukan pula sebagai bagian yang terintegrasi dalam pertunjukan Rabab Pasisia. Penelitian ini sampai pada kesimpulan bahwa keberlangsungan dan perubahan pada pertunjukan Rabab Pasisia Pesisir Selatan telah meluas menjadi suatu bentuk seni multifungsi.
\end{abstract}

Kata kunci: rabab; pasisia; sikambang; tutur

\section{Pendahuluan}

Rabab Pasisia adalah seni tutur yang berkembang pada masyarakat Pesisir Selatan, Sumatera Barat, dimana dalam pertunjukannya menggabungkan antara kaba atau cerita dengan iringan rabab. Pertunjukan musik Rabab di Minangkabau sebagai suatu kebudayaan yang memiliki berbagai macam dan jenis kesenian tradisional, satu dengan lainnya mempunyai ciri dan spesifikasi. Suatu perspektif atau pandangan luas masyarakat Minangkabau tentang kesenian Rabab Pasisia yang tumbuh dan berkembang di Pesisir Selatan saat ini sangat menarik untuk di perbincangkan. Khususnya tentang lagu Sikambang dalam pertunjukan Rabab Pasisia, baik di kalangan masyarakat penikmat seni maupun bagi seniman rabab itu sendiri. Secara umum penikmat seni dan seniman rabab itu sendiri memiliki konsep berfikir yang cukup berbeda, sesuai dengan sifat kesenian yang selalu berubah dan berkembang menurut pengaruh budaya yang datang dari luar.

Sejalan dengan perkembangan apresiasi masyarakat pendukungnya maka muncul pula berbagai lagu Sikambang (lagu pengantar kaba atau lagu pengantar cerita). Lagu tersebut mempunyai arti penting bagi pemain rabab itu sendiri maupun bagi masyarakat pendukungnya. Melihat begitu pentingnya lagu Sikambang sebagai lagu pengantar kaba maka sebelum masuk kecerita (bakaba)

1 Alamat korespondensi: Institut Seni Indonesia Padangpanjang. Jln. Bahder Johan Padangpanjang. Hp.: 081266858569. E-mail: tom_pstv@yahoo.co.id 
terlebih dahulu dibawakan lagu-lagu Sikambang, gunanya agar pita-pita suara menjadi longgar dalam arti kata pemanasan, dan di samping itu juga untuk memusatkan kosentrasi untuk memasuki cerita. Dilihat dari sisi masyarakat pendukungnya, kehadiran lagu-lagu sikambang berarti pertanda pemain rabab akan memasuki sebuah cerita, cerita tentang apa yang akan dibawakan oleh pemain rabab.

Lahirnya kesenian Rabab Pasisia ini berhubungan erat dengan seni tutur kaba yang dikenal dengan "Basikambang". Dendang Sikambang merupakan visualisasi penderitaan hidup dalam sejarah yang panjang di Pesisir Selatan, karena daerah ini telah lama menjadi jajahan, baik yang datang dari Portugis, Belanda, dan dari Aceh.

Akibat yang ditimbulkan penjajahan ini mengilhami terciptanya kekhasan irama lagulagu Sikambang yaitu irama sedih tentang nasib atau kehidupan yang selalu tertekan. Kehidupan menjadi sulit penuh dengan penderitaan, sehingga menjadi perenungan terhadap nasib yang malang, sedih penuh ratap tangis, baik sebagai bangsawan maupun sebagai rakyat biasa. Penderitaan ini lebih dirasakan lagi oleh seorang yang berstatus sebagai pembantu yang bernama Sikambang. Figur Sikambang dengan segala penderitaannya adalah lambang suatu kesedihan yang tiada taranya, tetapi kesedihanpun memiliki kualitas yang berbeda. Perbedaan tingkat kesedihan inilah yang dilahirkan dalam berbagai lagu Sikambang, sehingga suasana alur kaba (cerita) pun harus disesuaikan dengan kualitas kesedihan lagu-lagu Sikambang. Namun sampai saat ini lagu-lagu Sikambag ini tidak diketahui siapa penciptanya. Seniman-seniman pencipta zaman dulu (seniman tradisi) sangat hebat-hebat, namun mereka tidak ada yang mencantumkan namanya atas karya yang diciptakan (Yasa, 2016: 47). Sehubungan dengan itu (Udin, 1993: 14) mengemukakan bahwa lagu Rabab Pasisia terdiri dari empat kelompok, seperti: (1) Laila Ampalu Surantiah, Sikambang Data, Sikambang Lagan, Sikambang Aia aji; (2) Jarek Lokan; (3) Parasaian, Parantauan, Kalauik, Tembak Selang, Malereang, Kabungo, Kaburuang; (4) Tabang Sabalah, Gadih Basanai, Bujang Jauh.

Di lihat dari susunan lagu pembukaan, pada dasarnya susunan lagu yang diawali oleh lagu Laila
Ampalu Surantiah, dengan mengangkat suara pelan-pelan dan sedih. Sikambang data, suara dikembangkan secara mendatar membentuk irama dan lebih bersifat monoton. Sikambang Lagan, lagu terus berkembang, nadanya meningkat dan jatuh bagaikan air terjun. Sedangkan lagu Sikambang Aia Aji dimulai dengan nada-nada yang berayun dan bergelombang. Melalui lagu Sikambang Aia Aji ini, maka pemain sudah siap untuk memasuki lagu bagian kedua, yakni Jarek Lokan dengan perubahan tempo yang kontras dan gembira.

Musik dan aspek-aspek atau tingkah laku lainnya dalam kehidupan manusia memiliki keterkaitan, sehingga pemahaman mengenai suatu kebudayaan dapat dicapai antara lain lewat studi terhadap musiknya (Irawati, 2016: 3). Tradisi lisan merupakan sumber sejarah masa lampau yang merupakan pekerjaan penting tetapi sekarang sudah punah (Bramantyo, 2003: 35) dalam tulisannya menjelaskan bahwa tradisi lisan menduduki peranan yang penting di dalam dunia metaforik dan metafisik. Dengan demikian, tradisi lisan yang memenuhi khasanah seni pertunjukan patut dijaga, bukan untuk tidak dikembangkan secara kreatif, melainkan disublimasikan sehingga memiliki "Roh" yang baru inilah makna revitalisasi yang sesungguhnya.

Pemahaman musik rabab sebagai musik non barat yang mana transkripsi musik non barat dalam gaya notasi barat selalu menghasilkan beberapa bentuk distorsi (penyimpangan). Sistem nada musik kesenian tradisional Minangkabau umumnya menggunakan sistem nada diatonis yang berasal dari teori musik modern. Adanya usaha untuk mencari kemungkinan menemukan pola sistem nada yang didasarkan nuansa-nuansa yang digunakan dalam dendang atau lagu yang diangkat dari $k a b a$, maka baik dalam musik vokal maupun bentuk instrumental senantiasa tidak dapat dipisahkan dengan pembicaraan yang berkaitan dengan bentuk atau aspek musikologis itu sendiri. Aspek musikologis pada hakekatnya berkaitan dengan unsur-unsur yang membangun keutuhan musik. Sehubungan dengan permasalahan musik bahwa "Whatever the mixture of singers and/or instrumentalists may be, it should be mentioned as a first step in describing a music" (Malm, 1976: 7). 
Keberadaan musik tidak bisa dipisahkan dengan manusia sebagai pelaku. Dengan demikian musik Lagu Sikambang terbentuk oleh perilaku kehidupan masyarakat, medium musik maupun fungsinya. Refleksi gagasan maupun vokabuler yang dimiliki penulis baik tradisi maupun modern dalam suatu presentasi estetis musikalitas (Suneko, 2016: 62). Makna dan isi hanya dapat diinterpretasikan secara kongkrit oleh masyarakat pendukungnya. Karya seni mengandung makna, atau mengatakan tentang sesuatu, oleh karenanya dibutuhkan penafsiran dalam memaknainya sebelumnya dilakukan deskripsi pada suatu karya seni dari orang-orang yang membaca karya seni itu boleh saja sama dalam mendeskripsi dan setuju, tetapi dalam menafsir dan mengevaluasi boleh saja berbeda.

Dalam penelitian ini masalah musik merupakan materi pokok yang berhubungan dengan eksistensi lagu Sikambang dalam suatu penyajian musik rabab. Untuk mengkaji eksistensi tersebut, diperlukan suatu analisis terhadap materi musik itu sendiri. Penelitian ini dilakukan dengan metode deskripsi analisis, berdasarkan fenomena yang muncul dari masalah komposisi lagu Sikambang dalam konsep pertunjukan Rabab Pasisia. Untuk itu yang menjadi data primer dalam penelitian ini adalah tekstual lagu Sikambang dari hasil rekaman, sedangkan sebagai data sekunder dilakukan melalui wawancara, pendekatan literatur, dan pendekatan konsep musik yang relevan dengan pokok permasalahan.

\section{Asal-usul Rabab Pasisia}

Rabab adalah istilah secara umum yang dipakai oleh masyarakat pesisir Selatan (barabab). Sedangkan secara khusus masyarakat Kambang Kecamatan Lengayang mengungkapkan bahwa barab sama dengan babiola.

Istilah rabab bukanlah bahasa Minangkabau asli dan dalam bahasa Indonesia disebut "Rebab". Istilah rebab dan rabab sama-sama memiliki hubungan dan latar belakang sejarah perkembangan agama Islam ke Nusantara ini. Istilah rebab cocok untuk dialek bahasa melayu, sedangkan istilah rabab lebih sesuai dengan dialek bahasa Minangkabau yang cenderung memunculkan huruf vokal $a$ pada suku kata pertamanya. Kemudian dalam bahasa Arab dijumpai kata rabab secara lafadz berbunyi rabaabun atau rabaabatun, artinya sejenis bunyi biola. Mardjani Martamin menyatakan sebagai berikut. Rabab adalah salah satu unsur kebudayaan Islam. Fungsi rabab itu pada mulanya adalah sebagai alat dakwah Islam. Para kaum sufi sudah banyak melakukan kontemplasi untuk berhubungan dengan sang Khalik menggunakan musik (Frishkopf, 2012: 148-156). Seni Islam adalah sarana yang memungkinkan ruh Islam menembusi segala perkara dan bentuk aktifitas, menyerap ke seluruh kehidupan manusia untuk mengingatkan mereka akan kehadiran Tuhan kemanapun mereka melangkah (Ediwar, 2016: 31). Masuknya rabab tersebut ke Sumatera Barat di bawah oleh pedagang Islam. Bentuk rabab yang asli tidak dapat dikenal lagi, sedangkan bentuk yang ada di daerah Sumatera Barat adalah bentuk yang dibuat sesuai dengan kondisi setempat. Daerah pertama di Sumatera Barat yang masuk Islam adalah Pariaman. Maka dari daerah Pariaman rabab tersebut menyebar ketiga jurusan yaitu ke Pesisir Selatan, Pesisir Utara dan Pedalaman. Bentuk rabab yang ada di pedalaman berbeda dengan yang di daerah Pesisir, di mana di daerah Pesisir Selatan berbentuk seperti biola (Martamin, 1977: 59).

\section{Pertunjukan Rabab Pasisia}

Musik Tradisional Rabab Pasisia biasanya dipertunjukan pada konteks upacara yang ada hubungannya dengan adat istiadat masyarakat pemiliknya, misalnya pada waktu perhelatan perkawinan, turun mandi, dan upacara alek nagari. Pertunjukan rabab pasisia terbuka peluang untuk pemain alat musik (rabab, adok, orgen, tamborin), penyanyi dan penonton untuk saling berinteraksi, melalui syair dendang dan $k a b a$, dalam ruang dan waktu pertunjukan yang mereka alami bersama. Penyajian musik dapat berkedudukan sebagai bagian dari upacara, jenis musik seperti: do'a keagamaan, nyanyian wajib keagamaan, dan bunyi intrumen musik yang dipandang sakral wajib dihadirkan dalam upacara keagamaan (Dinda, 2014: 140). Hal ini berbeda dengan musik rabab 
yang penyajian musiknya tidak dipakai dalam konteks acara atau upacara keagamaan.

Richard Schechner, seorang teorisi teater, mengemukakan bahwa elemen-elemen yang terkait dalam pertunjukan adalah (1) performers; (2) director; (3) textlaction; (4) space; (5) time; (6) audience (Schechner, 2003: 62). Namun dalam hal rabab pasisia kategori director (sutradara) tidak relevan, karena sistem kesenian tersebut tidak memisahkan antara sutradara dan pemain.

\section{Mengenal Rabab Pasisia}

Komponen instrumen musik Rabab Pasisia yang ada di Kabupaten Pesisir Selatan mempunyai bentuk yang tidak jauh berbeda, kalaupun ada perbedaannya semua itu dapat diindikasikan sebagai kesenangan dalam berkreasi untuk membuat instrumen. Berikut adalah alat musik rabab yang digunakan oleh tukang rabab dalam pertunjukannya.

Rabab Pasisia dimainkan dengan posisi duduk, cara memegang penggesek dan cara menggesek ternyata kebiasaan tersebut sudah menjadi tradisi semenjak hadir dan berkembangnya Rabab Pasisia di Kabupaten Pesisir Selatan Sumatera Barat. Jika ditinjau dari segi teknis maka didapati berbagai teori-teori dan konsep yang lahir tanpa pengertian mekanisme yang jelas menurut kaidah fisiologis. Fisiologis menurut pandangan Grant Allen adalah 'kesenangan estetik' pada manusia yang ditimbulkan oleh karya seni yang merupakan kumpulan aktivitas subjektif dalam diri manusia, yang tidak punya hubungan langsung dengan fungsi vitalnya, tetapi hanya menyentuh terminal

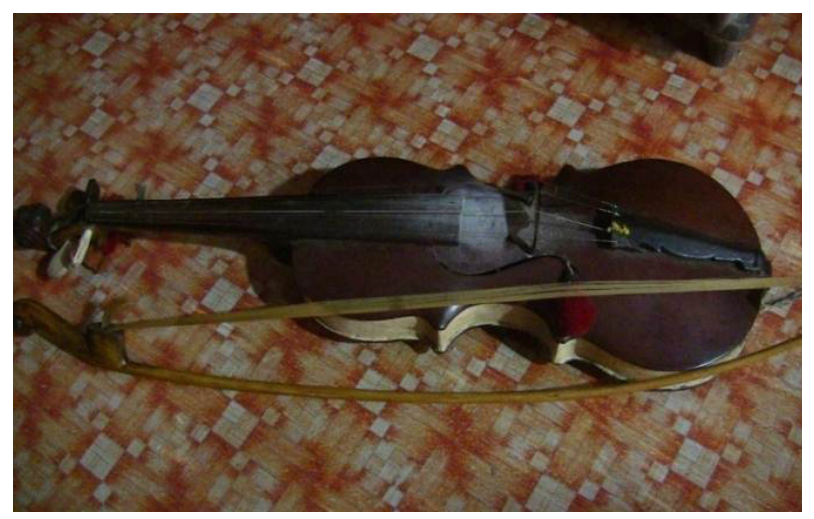

Gambar 1. Alat instrumen rabab yang digunakan dalam pertunjukan. (Foto: Hartitom, 2018) organ pikiran sistem saraf otak manusia (Jakop Sumardjo, 2002: 298). Setiap pemain rabab atau pendendang bermain dengan insting dan kemampuan serta sesuai dengan perkembangan bakat masing-masing melalui pengalaman yang didapat oleh tukang rabab atau (pemain rabab).

\section{Lirik Lagu (Teks Lagu)}

Teks lagu merupakan salah satu unsur media ungkapan dari seni vokal lirik lagu Sikambang ini disebut juga dengan pantun. Lirik lagu yang terdapat pada lagu Sikambang adalah aa-bb dan cc seperti gurindam tetapi baris satu dan dua, tiga dan empat, lima dan enam tidak berbalas tetapi hanya bercerita. Sedangkan pada baris ketiga terjadi pengulangan dua kali pada baris ketiga terjadi pemengalan dan penambahan huruf e dan o serta kata ondeh. Seperti bentuk lirik berikut.
Delah didalam o, la...ngik...
Nyarak lah pali...to, di dalam o...la...ngik
E...anaklah garudo, yo mamak, lah
pulanglah man...di...
Anaklah garudo, yo mamak, lah pulang o ma.. onde mandi...

Olah bak alang, manyonsong, lah angin ei... Coitu lah da o, untuang diri bao pulanglanh dagang di ra...ntau, lah pulang ei.

Dari gurindam ini dapat dilihat bahwa terjadi penambahan huruf ataupun pemenggalan kata yang merupakan kekhasan bahasa gurindam di Minangkabau dalam membawakan vokal. Terjadinya penambahan huruf ataupun pemenggalan

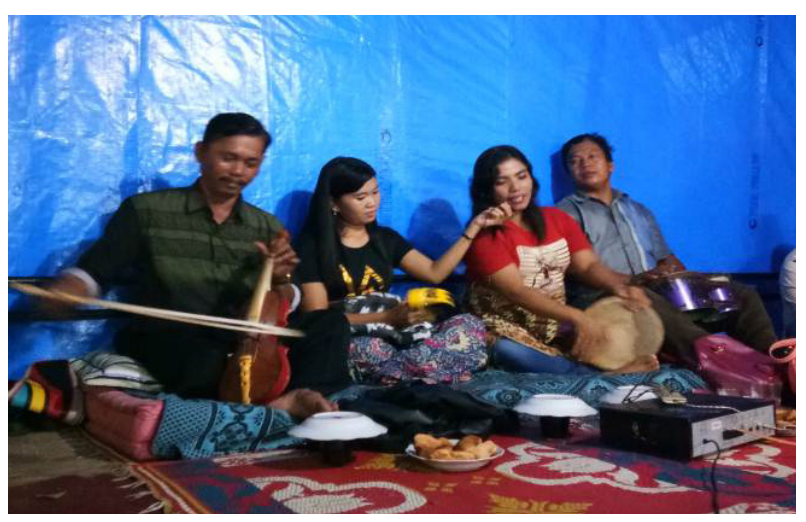

Gambar 2. Pertunjukan musik rabab dalam acara pesta pernikahan. (Foto: Hartitom, 2018) 
kata diakibatkan dari penyesuaian syair (teks lagu) dengan musik.

Kalau dilihat dari penempatan kata dengan pola-pola melodi dalam instrumen terdapat ketidak teraturan. Setiap suku kata tidak dapat diwakili oleh satu nada, dan kadang-kadang satu suku kata diwakili oleh beberapa deretan nada ataupun sebaliknya. William P. Malm mengatakan sebagai berikut.

"In Vocal music, another inportant characteristicis the relation of music to text. When one note is used for each syllable of the text, the style is syllabic. If one syllable is used with many notes, the style is melismatic. The study of text also offers opportunities for finding relations between language accents and music accents as well as musical reactions to important or colorful words in the poem" (Malm, 1997: 9)

Untuk memperjelas bentuk gurindam dalam bentuk penambahan huruf dan pemenggalan kata tersebut dapat dituliskan melalui deskripsi berikut.

Deh lah di dalam langik

Nyarak lah palito di dalam langik

Anaklah garudo yo mamak, lah pulang mandi $2 x$

Lah bak alang manyonsong angin

Coitulah untuang diri

Bao pulang dagang di rantau

[Ondeh lah di dalam langit

Terang pelita di atas langit

Anak garuda pulang mandi

Ibarat elang menyongsong angin

Seperti itulah untung diri

Bawah pulang orang di rantau]

Dengan demikian jelaslah bahwa syair (teks) pada lagu Sikambang terbentuk dalam satu gurindam, pada sampiran dan isi bersajak a a yang terdiri enam baris. Isi dan makna tersirat yang terkandung dalam syair ini hanya dapat dimengerti dan dipahami oleh para pendukung Rabab Pasisia itu sendiri. Adapun makna musikal dapat ditemukan dengan menghubungkan unsur-unsur bunyi, nada, ritme, melodi, harmoni, tonalitas, bentuk, isi, nilai, analisa, ekspresi, pertunjukan, hingga kebudayaan (Sukistono, 2014: 185).

\section{Ekspresi}

Ekspresi atau interpretasi yang dibawakan oleh pemain rabab sangat berbeda dengan konteks musik Barat. Ekspresi musikal adalah ekpresi emosional yang artistik dengan menggunakan nadanada, yang diatur menurut aturan-aturan tertentu, yang di dalam tradisi musik Barat aturan-aturan itu sudah berwatak ilmiah. Ekspresi linguistik memerlukan penjelasan yang berbeda dari ekspresi musikal (Tyasrinestu, 2014: 164-165). Ekspresi pada musik Barat didasarkan pada struktur musik yang telah ditulis melalui simbol dan tanda musik. Hal yang paling penting dalam sebuah karya seni adalah ekspresi perasaan, yaitu ekspresi dalam pengertian yang logis, yang menyajikan susunan kepekaan emosi serta alur pikiran yang serentak (Slamet dan Djohan, 2017: 69). Ekspresi dalam musik tradisi khususnya dalam lagu Sikambang ditentukan oleh suasana dan tempat pertunjukan. Apabila suasana dan tempat pertunjukan sesuai yang diinginkan oleh pemain rabab maka timbulah perasaan senang dalam menyajikan rabab sehingga ekspresi yang muncul dari pemain tidak dibuat-buat melainkan ekspresi lahir dalam jiwa pemain itu sendiri.

Dendang yang dibawakan dengan iringan musik yang bernuansa atau bertema parasaian, kegagalan, kekecewaan dan seterusnya, apabila secara spontan membawa dampak pada masyarakat untuk mengekspresikan emosionalnya, seperti: meneteskan air mata (sedih) dan terharu, maka dikatakan bahwa sajian dendang yang ditampilkan tersebut mempunyai fungsi ekspresi emosional (Rustiyanti, 2014: 159-160). Ekspresi para musisi pada kesenian tradisi talempong bundo sejalan dengan ekspresi wajah seluruh pelaku upacara yang kelihatan amat tenang dan sederhana. Ekspresi masing-masing pelaku upacara disatukan oleh sajian musik sehingga membentuk satu kesatuan simbol yang mengantarkan para penikmatnya berhubungan dengan alam semesta. Pengungkapan ekspresi para musisi tidak berpengaruh terhadap tempo lagu (gua), sehingga tempo lagu dari awal hingga akhir pertunjukan selalu konstan dan hampir tidak berubah sama sekali (Sriwulan, 2014: 61). Dalam seni pertunjukan musik Rabab Pasisia, ekspresi juga sangat ditentukan oleh penonton. 
Apabila penonton memberikan semacam tepuk tangan atau berteriak terhadap pemain rabab maka pemain itu sendiri lebih bersemangat dalam memainkan rabab-nya.

\section{Makna Musikal}

Makna musikal pada lagu Sikambang dapat dilihat dari lafal lirik lagu. Untuk mempermudah pemahaman mengenai makna yang selalu berubah, suatu karya seni bisa dipahami sebagai sebuah teks. Lirik lagu yang terdapat dalam lagu Sikambang awalnya berakar dari suatu cerita rakyat. Lirik lagu tersebut disusun mengandung makna kias dengan nilai sastra yang sangat tinggi bagi masyarakat di Pesisir Selatan. Makna pocapan dan lagu tidak dapat dipisahkan. Kesan rasa yang ditimbulkan oleh lagu dengan kesan suasana yang dibangun oleh kalimat dilihat dalam konteks pertunjukan sebagai sebuah struktur yang mendukung makna pemain secara keseluruhan (Harpawati, 2015: 156). Dari cerita yang didendangkan tersebut berkembang ke dalam sastra bahasa yang berbentuk gurindam. Tidak dapat dibedakan bentuk sampiran dan isi seperti halnya sastra pantun dengan tegas bersajak $a-b, a-b$. Pengunaan pantun yang mempunyai makna dalam pertunjukan rabab hanya dapat ditentukan dari persepsi masyarakat terhadap kesan yang mereka peroleh dalam menyaksikan satu pertunjukan.

\section{Gaya Musik (Musical Style)}

Gaya musik merupakan satu komponen musik yang berhubungan dengan identitas musik dalam kelompok masyarakat, baik secara nasional maupun regional. Dalam istilah musik Latifah (1989: 70) menyatakan bahwa stile adalah corak atau gaya bahasa. Soeharto (1992: 42) memberi penjelasan bahwa gaya menyangkut dengan ciri khas yang selalu kelihatan atau terasa dari suatu karya seni. Dapat bersifat perorangan maupun kelompok, baik kelompok ruang (daerah, negara), maupun waktu, masa, zaman. Untuk melihat suatu gaya musik dalam komposisi Sikambang, secara khusus gaya musik dapat dianalogikan pada kesan yang timbul dari pertunjukan musik secara kualitas subjek yang merupakan kesan musik muncul diukur dari penekanan emosional isi dan makna musik. Secara teoritis yang sering didengar bahwa keberadaan suatu gaya nyanyian merupakan cerminan karkteristik orangnya atau budayanya. Perilaku budaya seseorang atau masyarakat dibentuk oleh lingkungan dan budaya tradisinya itu sendiri, yaitu alam, perwatakan manusianya, sistem sosial yang dijalankan, sejarah yang telah dilaluinya, dan keyakinan masyarakatnya (Mistortoify, 2014: 12) Sedangkan gaya pada pertunjukan musik Rabab Pasisia juga dapat dicermati dalam kualitas objek, hanya dapat diukur melalui keseimbangan struktur musik dalam pemenuhan kerangkanya.

\section{Pelaku Rabab Pasisia}

Pemain Alat Musik dan Penyanyi Pertunjukan rabab memiliki pemain dan sekaligus sebagai penyaji utama dalam pertunjukan rabab. Pemain rabab lebih dikenal dengan sebutan tukang rabab. Tukang rabab merupakan istilah yang digunakan oleh masyarakat Pesisir Selatan untuk penyebutan seorang pemain rabab yang berperan langsung sebagai pemain utama dalam pertunjukan rabab. Penyebutan untuk pemain rabab dalam kesenian tradisional dapat diartikan sebagai orang yang ahli dalam memainkan instrumen rabab. Keahlian yang dimiliki tukang rabab dinilai dari kepiawaiannya dalam memainkan rabab wawasannya yang luas untuk menyampaikan kaba.

Tukang rabab juga dituntut untuk menguasai bahasa dan sastra Minangkabau dan memahami adat istiadat dan Agama. Yang paling terkhusus dari eksistensi seorang tukang rabab dapat dilihat dari keahliannya menguasai pantun-pantun Minang dan menyampaikan dengan spontan.

Biasanya tukang rabab yang berhasil dan terkenal serta memiliki jam tampil lebih banyak disebabkan oleh hasil kegigihan dalam belajar disaat mereka masih muda. Selain itu juga disebabkan oleh dorongan kondisi dimana masa muda mereka memiliki pengalaman pahit dan kecewa. Dari pengalaman pahit itulah mereka salurkan melalui permainan rabab. Seseoang yang akan menjadi tukang rabab yang profesional harus mempunyai fisik serta kemampuan tubuh yang kuat, memiliki wawasan yang luas untuk memberikan cerita khusunya pada 
$k a b a$, menguasai bahasa dan sastra Minangkabau, memahami adat istiadat Minangkabau serta agama, mampu menguasai pantun-pantun Minang serta memberikan pantun dengan spontan tanpa harus terlalu lama berfikir, dan memiliki kemampuan yang tinggi dalam babiola.

Pemain rabab umumnya petani. Pada siang hari mereka bekerja di sawah atau ladang, pada malam harinya mereka bermain rabab. Biaya pementasan dalam sekali pentas sekitar Rp. 2.000.000,-. Kehadiran bentuk sajian rabab, tidak dapat terlepas dari peran pemain atau tukang rabab sebagai pelaku dalam pertunjukan rabab. Berhasil atau tidaknya suatu pertunjukan rabab tergantung pada tukang rabab yang membawakannya. Jumlah pemain dalam pertunjukan rabab sesuai dengan kebutuhan acara yang akan diikuti. Jumlah pemain rabab dalam pertunjukannya idealnya adalah 4 sampai 6 orang yang memiliki peranannya masingmasing.

Pelaku dalam pertunjukan memegang alat musik yang berbeda-beda sesuai dengan perannya. Tukang rabab memegang alat musik rabab, perempuan memainkan alat musik tamburin, sekaligus sebagai pedendang, tukang adok dan gendang. Dalam sebuah pertunjukan tukang rabab sangat dituntut untuk mahir dalam merangkai kata-kata berbentuk pantun sekaligus mahir dalam memainkan rabab. Dari kemahiran inilah ukuran kualitas tukang rabab dapat dinilai oleh masyarakat.

Keberhasilannya dalam menghadirkan pertunjukan rabab menjadikan tukang rabab memiliki eksistensinya tersendiri pada masyarakat Pesisir Selatan. Keberhasilan suatu pertunjukan rabab tidak hanya diperankan oleh tukang rabab saja, akan tetapi juga oleh pedendang atau penyanyi

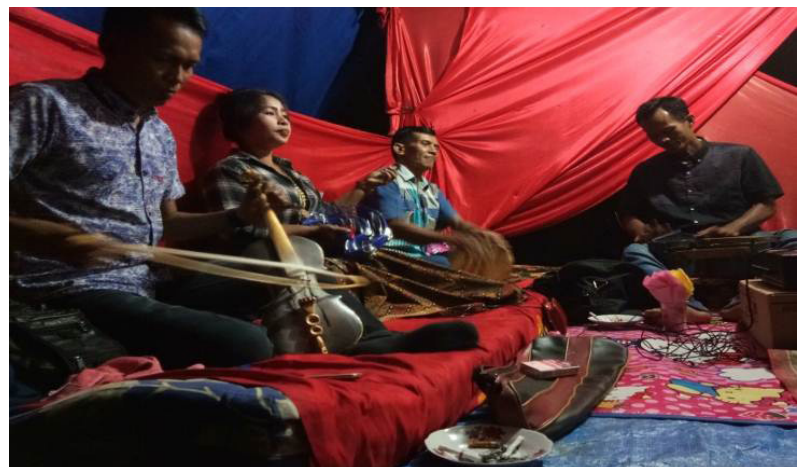

Gambar 3. Pertunjukan rabab tradisi dengan jumlah pemain 4 orang. (Foto: Hartitom, 2018) perempuan dan dua orang pemain laki-laki lainnya. Pedendang perempuan atau lebih dikenal dalam masyarakat Pesisir Selatan adalah padendang padusi (dalam bahasa Minang). Padendang perempuan dalam pertunjukan rabab juga memiliki perannya tersendiri sebagai pedendang karena terkadang ada beberapa bagian kaba dan dendang disampaikan secara bergantian antara tukang dendang dan padendang perempuan yang kadang kala juga bersautan. Padendang perempuan juga memainkan alat musik Tamburin yang digunakan ketika pertunjukan rabab dalam suasana gembira.

Dalam pertunjukan rabab awalnya tidak ada perempuan sebagai pemain rabab atau tukang dendang dan penyanyi, namun saat ini sudah banyak dijumpai perempuan sebagai pemain dalam setiap pertunjukan rabab. Bahkan pedendang perempuan menjadi daya tarik tersendiri bagi penonton dalam menyaksikan pertunjukan rabab.

Menjadi pedendang perempuan dalam pertunjukan rabab dapat menghibur penonton yang menyaksikannya. Pandangan positif terahadap pedendang perempuan adalah dapat menghasilkan uang dan dapat membantu perekonomian keluarga. Sedangkan penilaian negatif dapat dilihat dari segi waktu yang digunakan untuk pertunjukan adalah di malam hari dari jam 09.00 - 04.00 wib, waktu dimana seorang perempuan di Minangkabau sangat tidak pantas untuk berada di luar rumah pada waktu yang dianggap sudah malam. Selain waktu yang menjadi penilaian negatif dari sisi seorang pedendang perempuan, juga dikarenakan penonton pada pertunjukan rabab umumnya adalah kaum laki-laki. Diantara kaum laki-laki sebagai penonton terkadang banyak terdapat ninik mamak yang juga ikut menyaksikan pertunjukan rabab, maka dari itu

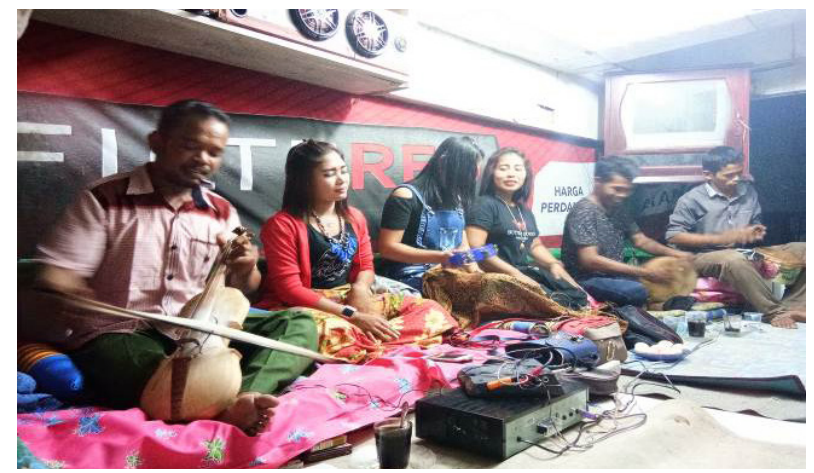

Gambar 4. Pertunjukan rabab tradisi dengan jumlah pemain 6 orang. (Foto: Hartitom, 2018) 
banyak norma-norma yang nantinya akan menjadi sumbang ketika kehadiran pedendang perempuan di dalam pertunjukan rabab.

Pakaian yang digunakan dalam pertunjukan juga banyak menjadi sorotan apabila pedendang perempuan tidak menggunakan pakaian yang sopan dan pakaian yang seharusnya digunakan. Dilihat dari pertunjukan rabab yang diamati, pakaian atau busana yang digunakan pedendang perempuan dalam pertunjukannya terlihat sopan dengan menggunakan kain sarung untuk menutupi kaki sebagai pengganti rok. Kain sarung digunakan bertujuan agar ketika pedendang perempuan duduk dan berhadapan dengan penonton terlihat menutupi bagian kaki.

Pedendang perempuan berusaha menjaga pandangan penonton disaat pertunjukan. Sebagian besar penonton adalah laki-laki, maka dari itu pedendang perempuan harus menyesuaikan pakaiannya disaat pertunjukan. Penyajian Rabab Pasisia, sesuai dengan adat yang berlaku di Kambang, disamping disediakan tempat oleh tuan rumah tersebut juga diberikan beberapa perlengkapan seperti; kasur dan bantal yang

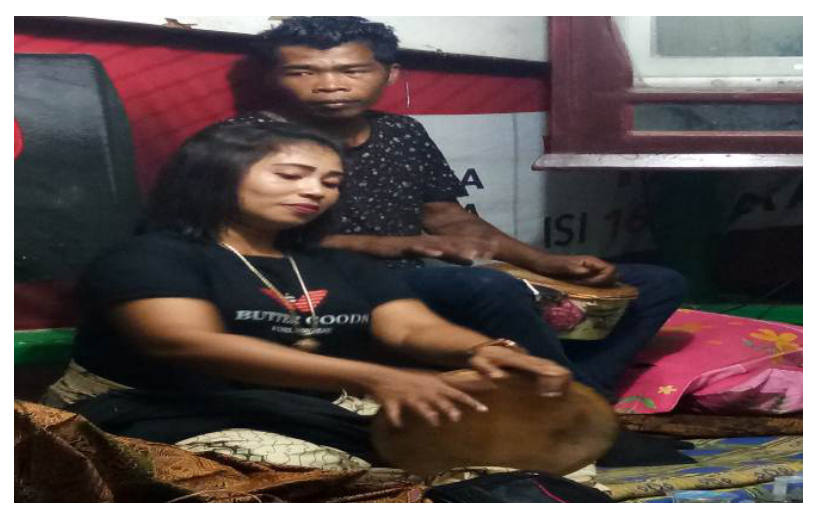

Gambar 5. Perempuan sebagai pemain Adok. (Foto: Hartitom, 2018)

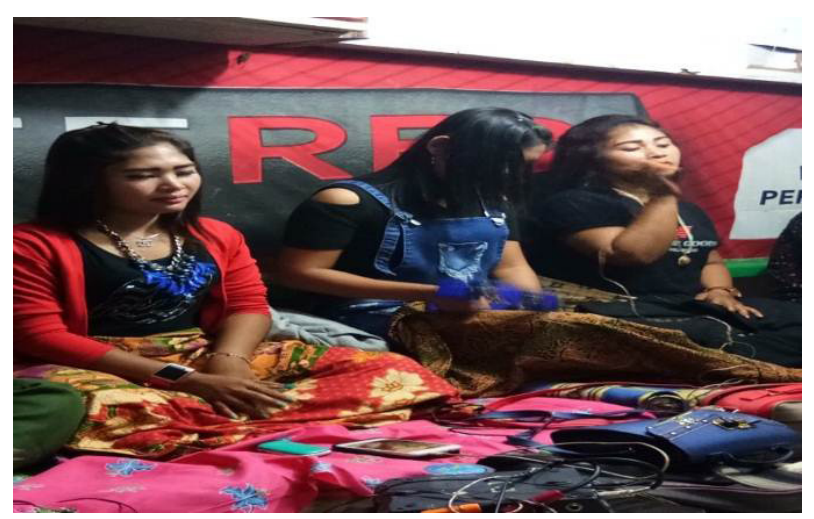

Gambar 6. Kain sarung yang menutupi kaki pemain rabab perempuan. (Foto: Hartitom, 2018) diletakan disebelah kamar penganten atau di samping tempat duduk mempelai laki-laki dan wanita bersanding, dan di tempat itulah pemain rabab menyajikan pertunjukan rabab-nya.

\section{Waktu Pertunjukan}

Waktu pertunjukan musik Rabab Pasisia ini dibagi atas dua tahap yakni; tahap pertama, dilakukan dari pukul 20.00 WIB sampai pukul 24.00 WIB. Pada tahap pertama ini lagu-lagu atau dendang-dendang yang dibawakan dendang gembira seperti; Raun Sabalik, dan dendangdendang Ginyang. Tahap kedua, waktu penyajian yang tepat untuk membawakan lagu-lagu Sikambang dengan teks kaba biasanya dimulai pada larut malam yaitu sekitar 24.00 sampai pukul 5.00 pagi. Suasana interval waktu ini sangat cocok untuk mendukung karakter musik lagu-lagu Sikambang. Menurut adat yang berlaku di Kambang syarat untuk menampilkan Rabab Pasisia sebagai berikut: (1) Tabantang tabie nan panjang, takambang lapiak nan putiah; (2) Tatagak Lamin (pelaminan), talatak sirieh jo carano; (3) Tapasang tirai langik-langik, rabah taranak kaki ampek.

Sejalan dengan perkembangan dan perubahan, syarat tersebut dalam penyajian rabab saat ini tidak mutlak untuk diberlakukan dalam setiap pertunjukannya, sehingga bersifat fleksibel dan disesuaikan dengan konteks pertunjukan.

\section{Penonton}

Penonton merupakan subjek yang dapat merespon objek yang ditampilkan. Penonton



Gambar 7. Penyajian rabab organ yang terlepas dari aturan adat di arena panggung terbuka. (Foto: Hartitom, 2018) 
adalah salah satu unsur yang penting di dalam pertunjukan rabab, penonton juga merupakan orang yang terlibat langsung dalam peristiwa pertunjukan rabab. Dalam hal ini, kesenian rabab merupakan kesenian yang disuguhkan langsung oleh atau pemain rabab kepada penonton.

Seseorang atau sekelompok orang dikatakan sebagai penonton, apabila ada sebuah pertunjukan yang ditonton. Suatu aktivitas baru disebut tontonan apabila ia dilakukan dengan kesengajaan maksud untuk dilihat oleh orang lain, dipertontonkan atau digelar (Simatupang, 2013: 64-65). Penonton merupakan orang-orang atau sekelompok manusia yang sengaja datang untuk menyaksikan sebuah pertunjukan dalam berbagai bentuk penyajian. Penonton dapat dikatakan sebagai apresiator, penikmat, dan juga penilai suatu pertunjukan.

Pertunjukan rabab tidak membatasi penonton dari lapisan masyarakat manapun, rabab merupakan pertunjukan hiburan bagi masyarakat pendukungnya karena pertunjukan rabab sebagai kesenian tradisi yang tumbuh dan berkembang dalam kehidupan masyarakat Pesisir Selatan, sehingga memiliki nilai-nilai budaya sebagai pelindung, penikmat, pelaku penyelenggara atau penanggung jawab dari kesenian rabab yang mereka lestarikan secara bersama-sama.

Penonton adalah salah satu unsur yang penting di dalam pertunjukan rabab, penonton juga merupakan orang yang terlibat langsung dalam peristiwa tersebut. Ketika penonton yang menghadiri sebuah pertunjukan seni pertunjukan rabab, di dalam diri mereka terdapat sejumlah jalinan pengalaman yang mengantarkan pemahamanya pada pertunjukan yang disaksikan. Di saat tukang rabab memainkan rabab dengan melantunkan lagu-lagu dalam sebuah $k a b a$, kadang terjadi reaksi dari penonton dengan melontarkan kata "agiah taruib" (lanjutkan terus). Reaksi dari penonton merupakan kepuasan terhadap sebuah sajian pertunjukan. Penonton pastinya menginginkan materi sajian yang menyenangkan dan apabila sebuah sajian pertunjukan itu tidak mengecewakan atau pertunjukan itu memuaskan penonton, sikap spontanitas dari penonton di atas biasa terjadi dalam sebuah pertunjukan rabab. Oleh sebab itu, penonton dikatakan sebagai unsur yang sangat penting dalam suatu pertunjukan. Penonton dalam hal ini bisa dikategorikan menjadi dua yaitu penonton aktif dan penonton pasif.

\section{Penonton Aktif}

Penonton aktif dalam kategori ini adalah penonton yang memberikan respon terhadap pertunjukan rabab. Respon penonton yang ditimbulkan dari perasaan menikmati dan perasaan masuk ke dalam suasana pertunjukan rabab yang dihadirkan oleh para pemain rabab. Penonton aktif biasanya selalu menantikan kehadiran dan aksi tukang rabab. Pada kategori ini tukang rabab harus mampu membangkitkan perasaanperasaan penonton dalam berbagai suasana. $\mathrm{Hal}$ ini dikemukakan oleh Simatupang yaitu.

Dalam sebuah peristiwa pergelaran Simatupang menjelaskan tiga sifat tontonan yaitu: (a) kehendak untuk mempergelarkan sesuatu, (b) ketidakbisaan (extraordinariness) sebagai daya tarik tonton; dan ada peristiwa yang mempertemukan antara maksud penyaji untuk menggelar dengan harapan penonton untuk mengalami sesuatu yang tidak biasa, (c) Sebuah pertunjukan yang menghadirkan peristiwa-peristiwa tak biasa (extraordinary) tersebut bisa dijadikan sebagai sebuah daya tarik di dalam pertunjukan itu sendiri dan hal inilah yang memotifasi seseorang untuk menonton pertunjukan (Simatupang, 2013: 65).

Pertunjukan rabab adalah gabungan dari vokal dan bunyi-bunyian dari instrumen rabab. Vokal dalam pertunjukan rabab berupa kaba yaitu cerita yang bersifat sedih. Maka dari itu dalam pertunjukan rabab suasana yang sering hadir adalah suasana sedih, dalam hal ini tukang rabab seolah-olah membangkitkan semua perasaan penonton tentang gambaran kehidupan yang dianggap kurang beruntung, sehingga tidak sedikit penonton yang larut dalam suasana yang didendangkan tukang rabab hingga banyak yang tidak menyadari air matanya (penonton) jatuh dengan sendirinya. Pada suasana ini satu diantara penonton memberikan respon dengan sorakan "heii ala heiii". Itu artinya penonton larut dalam suasana sedih yang dihadirkan tukang rabab. 
Satu kelompok pertunjukan Rabab Pasisia memiliki performer (pemain) dan audience (penonton) sehingga membentuk suatu atraksi dan interaksi. Komunikasi yang terjadi lewat pengirim pesan (pelaku pertunjukan) yang selalu memiliki maksud/tujuan (intention), sedang penikmat/ penonton memiliki perhatian (attention) dalam menerima pesan. Selama pertunjukan berlangsung, agar tidak menimbulkan berbagai macam pertanyaan, pihak pengirim pesan (performer) dan penerima pesan (audience) selalu mengikuti pertunjukan. Itu artinya interaksi yang dilakukan oleh pemain dan penonton dalam pertunjukan rabab akan menentukan tujuan dan maksud dari kaba yang disampaikan oleh tukang rabab.

Penonton dalam pertunjukan rabab tidak memiliki aturan tertentu dalam menyaksikan pertunjukan. Lazimnya hanya memerlukan satu buah kasur dan bantal sebagai pengganti panggung, jelasnya dapat dilihat pada gambar 8 .

Penonton dalam hal ini tidak hanya sekedar menyaksikan pertunjukan, tetapi juga memberi respon terhadap kaba yang didendangkan oleh pemain rabab. Simatupang menyatakan pengalaman partisipan non penyaji dalam pergelaran tdak hanya sebatas pengalaman visual belaka, namun mereka juga mendengar, merasa, membaui, dan merasakan keseluruhan atmosfer pergelaran (Simatupang, 2013: 70). Sejalan dengan pernyataan di atas, respon penonton dalam pertunjukan rabab terlihat pada sautan penonton ketika pemain rabab berhasil menyindir dalam bentuk dendang atau semacam pantun jenaka yang dapat memecahkan suasana pada saat pertunjukan rabab berlangsung. Tukang rabab dituntut untuk membangkitkan

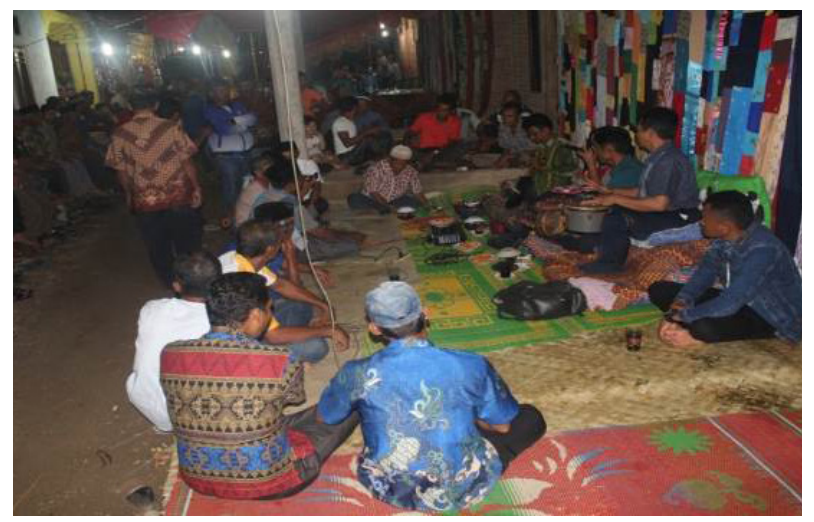

Gambar 8. Penonton sedang menyaksikan aksi dan reaksi permainan rabab. (Foto: Hartitom, 2018) perasaan-perasaan tertentu dikalangan penonton. Pertunjukan rabab dikatakan berhasil diukur oleh respon penonton yang diberikan atas aksi para pemain rabab. Ketika tukang rabab menyampaikan kaba dalam bentuk ratapan, dengan sendirinya penonton yang menikmati akan terbawa dalam suasana sedih yang disampaikan tukang rabab bahkan ada penonton yang menangis, demikian pula saat pantun dilantunkan, penonton merasa terhibur.

Pertunjukan rabab dengan irama dan syairsyair yang syahdu dapat mengunggah perasaan pendengar dan penontonnya, sehingga hubungan antara musik rabab dengan pendengarnya dapat tercipta dengan sendirinya.

\section{Penonton Pasif}

Penonton pasif adalah orang-orang yang hanya bermaksud untuk melihat atau menonton saja dan tidak memberikan respon terhadap pertunjukan dan aksi yang dilakukan tukang rabab. Penonton dalam kategori ini adalah penonton yang tidak menikmati pertunjukan dan tidak masuk dalam suasana yang dihadirkan para pemain rabab. Berikut adalah salah satu penonton pasif dalam pertunjukan rabab yang diadakan dirumah salah satu masyarakat Kambang, Pesisir Selatan.

Penonton pasif biasanya hanya sekedar mendengar sambil melakukan aktivitas lain, namun aktivitas itu masih ditempat pertunjukan rabab berlangsung. Penonton pasif tidak mengikuti pertunjukan dalam waktu yang lama hanya dimanfaatkan untuk istirahat setelah menikmati jamuan makan malam pada acara pernikahan sambil menikmati suguhan kopi.

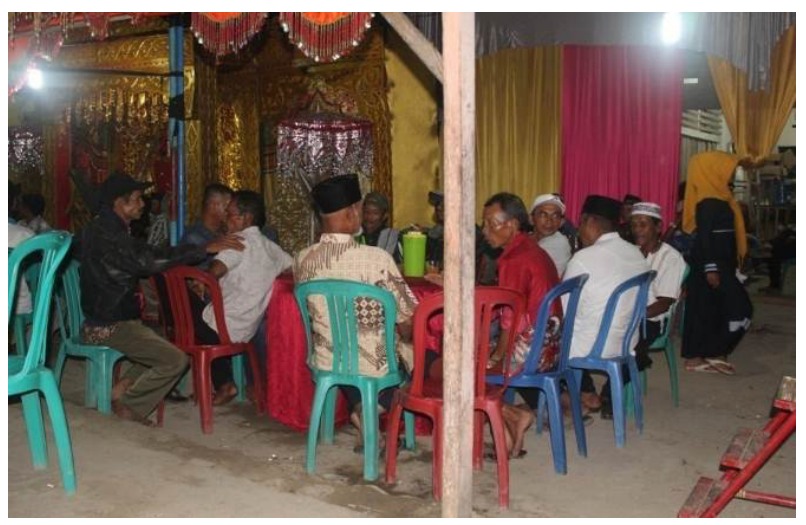

Gambar 9. Menonton pertunjukan rabab sambil bercengkerama. (Foto: Hartitom, 2018) 


\section{Penutup}

Pertunjukan Rabab Pasisia biasanya ditampilkan pada acara-acara adat masyarakat setempat atau hajatan seperti: pesta perkawinan, khitanan, pengangkatan penghulu (tagakpanghulu), pemberian gelar pada pemimpin suku masyarakat (batagak gala)dan lain sebagainya. Terdapat dua kategori tempat dan ruangan khusus untuk pemain atau padendang yaitu, di dalam dan di luar ruangan. Biasanya disaat upacara adat, seperti tagak panghulu atau batagak gala, tempat pertunjukan rabab di dalam rumah, tetapi kalau rumah tidak memadai untuk melakukan pertunjukan rabab, maka diperbolehkan pertunjukan di luar rumah seperti dibuatkan panggung kecil di depan atau di samping rumah. Tempat pertunjukan yang berada di luar ruangan biasanya yang bersifat acara hiburan pribadi seperti acara-acara baralek (perkawinan), akikah anak dan khitanan.

Pertunjukan Rabab Pasisia sebagai kesenian tradisi yang dimiliki masyarakat Pesisir Selatan memiliki arti dan makna tersendiri bagi setiap penikmat kesenian tradisi. Pertunjukan rabab sebagai sarana hiburan dan sekaligus sebagai sarana presentasi estetis yang berkaitan dengan budaya lokal masyarakat pendukung kesenian Rabab Pasisia.

Lagu Sikambang Aia Aji merupakan salah satu lagu pembukaan dari pertunjukan Rabab Pasisia. Gaya musik dari lagu Sikambang Aia Aji merupakan implementasi (penerapan) yang integral dari sosio kultural masyarakat, medium musik, dan fungsi musik yang diungkapkan melalui gaya musik yang berbentuk gaya objektif dan gaya subjektif. Gaya musik lagu Sikambang tidak hanya terbentuk oleh komponen struktur musik, tetapi juga dipengaruhi oleh sejarah, medium musik dan fungsi musik itu sendiri. Jelas bahwa teks lagu tersebut menunjukkan pengaruh terhadap sesuatu yang lain, tidak berdiri sendiri, justru dalam suatu hubungan tersebut memiliki arti dan makna sesuai dengan konteksnya dalam masyarakat Pesisir Selatan.

\section{Kepustakaan}

Bramantyo, Triyono.( 2003). "Konteks Semiotika Kesenian Dalam Kajian Kebudayaan”,
Kembang Setaman Persembahan untuk Sang Mahaguru. Yogyakarta: A.M. Hermien Kusmayati, (ed.), BP ISI Yogyakarta.

Ediwar. (2016). "Rekonstruksi dan Revitalisasi Kesenian Rapa'i Aceh Pasca Tsunami”, Resital Jurnal Seni Pertunjukan, 17 (1), 30-45.

Frishkopf, Michael. (2012). "Sufi Music: The Rough Guide to Sufi Music", Asian Music, 43, (1), 148-156.

Ganap, Victor.( 2003). "Kompleksitas Fakta Musikal”, Kembang Setaman Persembahan untuk Sang Mahaguru. A.M. Hermien Kusmayati, (ed.). Yogyakarta: BP ISI Yogyakarta.

Harpawati, Tatik., Lono L. Simatupang, Timbul Haryono, Sri Hastanto. (2015). "Keselarasan Lagu dengan Fungsi Pocapan dalam Pertunjukan Wayang Lakon Sundhamala", Resital Jurnal Seni Pertunjukan, 16 (3), 153-165.

Irawati, Eli. (2016). “Transmisi Kelentangan dalam Masyarakat Dayak Benuaq", Resital Jurnal Seni Pertunjukan, 17 (1), 1-17.

Kodijat, Latifah. (1989). Istilah-Istilah Musik. Jakarta: Penerbit Djambatan.

Malm, William, P. (1976). Music Cultures of The Pacific, The Near East, and Asia. New Jersey: Englewood.

Martamin, Mardjani, dkk. (1977). "Ensiklopedi Musik dan Tari Daerah Sumatera Barat". Jakarta: Departemen Pendidikan dan Kebudayaan.

Mistortoify, Zulkarnaen., Timbul Haryono, Victorius Ganap, Lono L. Simatupang. (2014). "Pola Kelleghan dan Teknik Vokal Kejhungan Representasi Ekspresi Budaya Madura dan Pengalaman Estetiknya", Resital Jurnal Seni Pertunjukan, 15 (1), 1-16.

Martarosa., Lono L. Simatupang, Timbul Haryono, Victorius Ganap,. (2016). "Apropiasi Musikal dan Estetika Musik Gamad”, dalam Resital Jurnal Seni Pertunjukan. Vol. 17 No. 1, April 2016: 19-29.

Rustianty, Sri. (2014). "Musik Internal dan Eksternal dalam Kesenian Randai", Resital Jurnal Seni Pertunjukan, 15 (2), 152-162.

Simatupang, Lono. (2019). Play and Display: Dua Moda Pergelaran Reyog Ponorogo di 
Jawa Timur, Terj., Y.R. Landung Laksono Simatupang. Yogyakarta: Program Studi Pengkajian Seni Pertunjukan dan Seni Rupa, Sekolah Pascasarjana Lintas Disiplin, Universitas Gadjah Mada.

Sukistono, Dewanto. (2014). "Pengaruh Karawitan terhadaap Totalitas Ekspresi Dalang dalam Pertunjukan Wayang Golek Menak Yogyakarta", Resital Jurnal Seni Pertunjukan, 15 (2), 179-189.

Simatupang, Lono. (2013). Pergelaran: Sebuah Mozaik Penelitian Seni Budaya. Yogyakarta: Jalasutra.

Slamet, R. Chairul., Djohan. (2017). "Musik Batu”, Resital Jurnal Seni Pertunjukan, 18 (2), 65-77.

Schechner, Richard. (2003). Performance Theory. London and New York: Routledge.

Sumardjo, Jakob. (2002). Filsafat Seni, Bandung: ITB.

Suneko, Anon. (2016). "Pyang Pyang Sebuah Komposisi Karawitan", Resital Jurnal Seni Pertunjukan, 17 (1), 62-66.

Soeharto, M. (1992). Kamus Musik. Jakarta: PT.
Gramedia.

Sriwulan, Wilma., Timbul Haryono, Victorius Ganap, Lono L. Simatupang. (2014). "Struktur, Fungsi, dan Makna Talempong Bundo dalam Upacara Maanta Padi Saratuih", Resital Jurnal Seni Pertunjukan, 15 (1), 52-70. Tyasrinestu, Fortuna. (2014). "Lirik Musikal pada Lagu Anak Berbahasa Indonesia”, Resital Jurnal Seni Pertunjukan, 15 (2), 163-168.

Udin, Syamsuddin. (1993). Rebab Pesisir Selatan Malin Kundang. Jakarta: Yayasan Obor Indonesia.

Upaja Budi, Dinda Satya. (2014). "Anglung Dongdong Lojor pada Upacara Seren Taun", Resital Jurnal Seni Pertunjukan, 15 (2), 139151.

Wijayanto, Bayu., Lono L. Simatupang, Victorius Ganap. (2015). "Strategi Musikal dalam Ritual Pujian dan Penyembuhan Gereja Kristen Kharismatik", Resital Jurnal Seni Pertunjukan, 16 (3), 125-140.

Yasa, I Ketut. (2016). "Aspek Musikologis Gender Wayang dalam Karawitan Bali", Resital Jurnal Seni Pertunjukan, 17 (1), 46-59. 